Volume: 13 Issue: 3 Year: 2016

\section{Effects of the project-based learning approaches on social skills, academic achievements and problem behaviors of students with mild intellectual disability ${ }^{1}$}

Proje tabanlı öğrenme yaklaşımının hafif düzeyde zihinsel yetersiz öğrencilerin sosyal becerilerine, akademik başarılarına ve problem davranışlarına olan etkisi

\author{
Mustafa Çevik $^{2}$ \\ Özge Çevik ${ }^{3}$
}

\begin{abstract}
The aim of this study is to determine effects of the project-based learning approaches on Social Skills, Academic achievements and Problem Behaviors of students studying at $3^{\text {rd }}$ grade primary school with Mild Intellectual Disability (MID) in sciences course. The participants of the research consisted of 10 students in Karamanoğlu Mehmetbey University from the Faculty of Education Integration Unit Pupa in $3^{\text {rd }}$ grade. In the study, pretest-posttest design, one group of pre-trial model, was used. To the students at the study, The Social Skills Rating System (SSRS) developed by Gresham and Elliot (1990) pretest - posttest was applied. SSRS, social skills and behavior problems that are considered to be associated with these skills of preschool and elementary school students was developed in order to determine their academic qualifications. In SSRS, there are three separate scales: Social Skill Scale, problem behavior subscale and academic achievement scale. To the students in the study, "I and my environment" topic was tauhgt with Project Based Learning Approach (PBLA) for 3 weeks, and the significance of the scores obtained by applying the scale before and after the course was examined. The data were analyzed by using
\end{abstract}

\section{Özet}

Bu çalışmanın amacı, fen bilimleri dersinde proje tabanlı öğrenme yaklaşımının ilkokul üçüncü sınıfta öğrenim görmekte olan hafif düzeyde zihinsel engele sahip öğrencilerin sosyal becerilerine, akademik başarılarına ve problem davranışlanına olan etkisini tespit etmektir. Araştırmanın katılımcılarını, Karamanoğlu Mehmetbey Üniversitesi Eğitim Fakültesi Pupa Öğrenci Entegrasyon Birimi'ne gelen hafif düzeyde zihinsel engele sahip 10 öğrenci oluşturmuştur. Araştırmada deneme öncesi modellerden tek grup ön test son test deseni kullanılmıştır. Çalışmada öğrencilere Gresham ve Elliot (1990) tarafindan geliştirilen, Özok ve Sucuoğlu'nun Türkçe'ye uyarladığı Sosyal Beceri Derecelendirme Sistemi (SBDS) öntest-sontest olarak uygulanmıştur. SBDS, okul öncesi ve ilköğretim öğrencilerinin sosyal becerileri ve bu becerilerle ilişkili olduğu kabul edilen davranış problemleri ile akademik yeterliliklerini belirlemek amaciyla geliştirilmiştir. Sosyal beceri dereceleme sisteminde üç ayrı ölçek bulunmaktadır: Sosyal beceri ölçeği, problem davranış alt ölçeği ve akademik yeterlilik ölçeği. Çalışmada öğrencilere üçüncü sınıf fen bilimleri dersinin "Ben ve Çevrem" konusu proje tabanlı öğrenme yaklaşımı ile 3 hafta boyunca işlenmiş

\footnotetext{
1 This study was presented at the 15 th International Primary Teacher Education Symposium (USOS) as an oral presentation.

2 Asist. Prof. Dr., Karamanoğlu Mehmetbey University, Faculty of Education, Department of Elementary Education, mustafacevik@kmu.edu.tr

${ }^{3}$ M.A., Ministry of Education, ozgecevik70@gmail.com
} 
Çevik, M., \& Çevik, Ö. (2016). Proje tabanlı öğrenme yaklaşımının hafif düzeyde zihinsel yetersiz öğrencilerin sosyal becerilerine, akademik başarılarına ve problem davranışlarına olan etkisi. Journal of Human Sciences, 13(3), 48494860. doi:10.14687/ihs.v13i3.4195

rank test signed non-parametric Wilcoxon on SPSS 16.0 software. At the end of the study, while there was a significant relationship between the scores of the participants' social skills based on the project-based learning approach, there was no significant correlation between problematic behavior scores. Furthermore there was also a significant difference between the scores of participants' academic competence. As a result, it can be said that the course tauhgt with PBLA improves social skills and academic achievement of students with MID. Despite the decrease in the problematic behavior scores of the students, no significance was observed.

Keywords: Project-Based Learning; Mild Intelligence Disability; Social Skill; Academic Efficacy; Problem Behavior.

(Extended English abstract is at the end of this document) ders öncesinde ve sonrasında ölçek uygulanarak elde edilen puanlar arasındaki anlamlliı̆ga bakılmıştır. Puanlar SPSS 16.0 programında non-parametrik Wilcoxon işaretli sıralar testi kullanılarak analiz edilmiştir. Çalışma sonunda proje tabanlı öğrenme yaklaşımı ile işlenen ders neticesinde katulımcların sosyal becerilerinin puanlarinin arasinda anlamllik bulunurken, problem davranış puanları arasında anlamlılık bulunamamıştır. Ayrıca katılımcıların akademik yeterliliklerine ilişkin puanlarının arasında da anlamll1k görülmüştür. Sonuç olarak proje tabanlı öğrenme yaklașımın hafif düzeyde zihinsel engele sahip öğrencilerin sosyal becerilerine ve akademik yeterliklerine olumlu katkısının olduğu söylenebilir. Öğrencilerin problem davranış puanlarında ise azalma olmasına rağmen anlamlılık bulunmamıştır.

Anahtar Kelimeler: Proje Tabanlı Öğrenme; Hafif Düzeyde Zihinsel Yetersizlik; Sosyal Beceri; Akademik Yeterlilik; Problem Davranış.

\section{GİRİŞ}

Gelişimsel yetersizlik, birey yaşamının erken dönemlerinde ortaya çıkar. Bu durum bireyin büyümesi ve yaşamını sürdürebilmesi için gereken becerileri edinmesinde hayatı boyunca etkili olacaktır. Gelişimsel geriliklerden biri olan zihinsel yetersizlik, bireyin zihinsel işlevler ile kavramsal, sosyal ve pratik uyum becerilerinde anlamlı sinırllıklar ve yetersizlikler görülmesi durumudur (Fidan Kurtdede ve Akyol, 2011). Zihinsel yetersizliği olan bireyler, engelden etkilenme derecesine bağl1 olarak kendi içerisinde eğitilebilir - öğretilebilir, ileri ve çok ileri derecede zihin engelli bireyler olmak üzere üç gurupta sınıflandırılır (Özsoy, Özyürek ve Eripek, 1997). Hafif düzeyde zihinsel engelli bireylerin eğitimlerini destek özel eğitim hizmetleri alması koşulu ile genel eğitim okullarında akranlarıyla birlikte sürdürmeleri olarak kabul edilir. Kaynaştırma yaklaşımı, son otuz yıldır yaygın olarak benimsenmekte, bunun sonucu olarak da bir çok ülkede engelli öğrenciler engelli olmayan akranları ile birlikte, genel eğitim okullarında eğitim görmektedirler (Sucuoğlu ve Özokçu, 2005). Ancak bu bireylerin eğitim süreci yalnızca normal sınıf ortamına yerleştirilmesini içeren bir süreç değildir. Aynı zamanda bu öğrencilerin gelişim düzeyini en üst seviyeye çıarabilmek amacıyla eğitim-öğretim ortam ve programını düzenleme ve bu süreçte bireye ihtiyacı olan destek ve düzenleme hizmetlerini sağlama uygulamalarını da içermektedir. Batu, Kırcaali-İftar ve Yıldız (2004), gerekli eğitsel kaynaklar, destek özel eğitim hizmetleri ve donanım sağlandığında kaynaştırmanın çok daha başarılı bir biçimde gerçekleştirilebileceği sonucuna ulaşmışlardır. $\mathrm{Bu}$ bireylerin gelişim özelliklerine, hazırbulunuşluk düzeylerine ve bulundukları eğitim basamaklarına uygun, etkili öğrenme yollarının öğretildiği eğitim basamaklarının en önemlisi ilkokuldur. Bu eğitim kademesinde öğrenciler için etkili öğrenmenin gerçekleştirilebileceği en uygun derslerden birisi ise fen bilimleri dersidir. Çünkü fen bilimleri dersi, içerisinde fizik, kimya ve biyoloji gibi disiplinleri barındıran ve günlük yaşantılarla ilgili temel becerilerin kazandırıldığı bir derstir. 
Çevik, M., \& Çevik, Ö. (2016). Proje tabanlı öğrenme yaklaşımının hafif düzeyde zihinsel yetersiz öğrencilerin sosyal becerilerine, akademik başarılarına ve problem davranışlarına olan etkisi. Journal of Human Sciences, 13(3), 48494860. doi: $10.14687 /$ ihs.v13i3.4195

Ülkemizde fen bilimleri dersi öğretim programının vizyonu; fen bilimlerinin teknoloji toplum - çevre ile olan ilişkisine yönelik anlayışa ve psikomotor becerilere sahip bireylerin yetiştirilmesi olarak tanımlanmıştır (MEB, 2013). Aynı zamanda bu ders, öğrencilerin sosyal becerilerinin gelişimlerinin de rahatlıkla gözlemlenebileceği bir derstir. 2005 yllından itibaren tüm öğretim programlarının yenilenmesi çalışmalarıyla birlikte özellikle fen öğretim programına uygun bazı öğretim yöntemlerini gündeme getirmiştir. Ön plana çıkan yöntemlerden en önemlilerinden birisi proje tabanlı öğrenme yaklaşımıdır (PTÖY). Öneminden dolayı öğrenme sürecinde PTÖY yaklaşımının kullanımının önemi artmış olup, bu durum yapılan birçok araştırmada ortaya konmuştur. Türkiye'de ve dünyada "Proje Tabanlı Öğrenme Yaklaşımı" konusu etrafinda yapılmış çok sayıda çalışma mevcuttur (Altun, 2008; Baran, 2011; Benzer, 2010; Demir, 2008; Girgin, 2009; Korkmaz, 2002). PTÖY genel olarak, öğrencilerin somut bir ürüne ulaşabilmesi amaciyla, bireysel veya grup olarak belirli bir süre çalışmalarını içeren bir yöntemdir. PTÖY diğer öğretim ve öğrenme yaklaşımları ile birlikte kullanılabilecek çok yönlü bir yöntemdir. Proje tabanlı öğrenme yönteminde kullanılabilecek yöntemler ve yaklaşımlar şöyle özetlenebilir. Bunlar;

\section{Problem Çözme Yöntemi}

2. Araştırmaya Dayalı Öğrenme Yaklaşımı

3. İşbirliğine Dayalı Öğrenme Yöntemi

4. Bilimsel Yöntem Sürecine Dayalı Öğrenme Yaklaşımı

5. ÇZK (Çoklu Zeka Kuramı)

6. Yapıcı (Yapılandırmacı) Öğrenme Kuramı (Çakallığlu, 2008).

Proje çalışmalarında temel amaç, öğrencilerin kendi öğrenmelerini takip etmelerini sağlamak, olumlu risk alma durumlarını geliştirmek ve işbirliği içerisinde çalışmaya istekli hale getirmektir (Bilen, 2002; Korkmaz ve Kaptan, 2002; Saban, 2000). Proje tabanlı öğrenme, öğrencinin, öğrenme öğretme sürecinde pasif bir alıcı konumundan, araştıran, inceleyen, bilgiye ulaşan ve elde ettiği bilgileri kullanarak anlamlı bütünler haline getirip bu bilgilerle problem çözmesini amaçlayan bir öğrenme modelidir (Özdener ve Özçoban 2004).

PTÖY ile birlikte öğrencilere bilimsel becerilerin kazandırılmasının yanında öğrencilerin ilgili disipline yönelik olumlu tutumlarını arttırmak ta hedeflenmektedir. Bu yaklaşım öğrencilerin akademik başarılarına, tutumlarına ve derse karşı ilgilerine olumlu katkılar sağlamaktadır. Özellikle bu yaklaşımın fen ve matematik gibi derslerde uygulanması birçok avantaj sağlayabilir. Son yıllarda hafif düzeyde zihinsel engele sahip öğrencilerin eğitiminde fen eğitiminin önemli bir yere sahip olduğu düşünülmekte ve bu kapsamda yoğun çalışmalar yapılmaktadır (Cawley, 1994; Mastropieri \& Scruggs, 1994; Patton, 1993; 1995). Fen eğitimi bu öğrencilerin düşünme ve problem çözme gibi yetilerinin geliştirilmesinde çok büyük avantajlara sahiptir (Woodward, 1994). Öğrenci bu derste yaşanılan hayatın içinden olayları ele alarak bu olaylardan hangi sonuçları çıkarması gerektiğini, insan ve vatandaş olarak görevlerini, sorumluluklarını öğrenir. Böylece küçük yaşlarda çocuğun hazırbulunuşluk düzeyine uygun olarak öğretilen bilgi ve becerilerin daha sonraki yaşam sürecine transfer edilip kullanılacağı düşünülmektedir (Akınoğlu, 2004). Ancak hafif düzeyde zihinsel engelli öğrenciler için bu derste hangi yöntemi, yaklaşımı veya öğretim programını uygulamak en uygunudur (Scruggs, Mastropieri, \& Bonn, 2008) sorusunun cevaplandırılması oldukça önemlidir. Bu öğrenciler için herhangi bir çalışma gerçekleştirilecekse duyuşsal seviyeleri ve benlikleri dikkate alınmalı, öğrencilerin aktif ve anlamlı katılımlarını gerçekleştirebilmek için gerekli hedefler ortaya konmalıdır (Bigge, Best, \& Heller 2001). Bu bağlamda uygulamaları ve sorgulayıcı özellikleri içinde barındıran yine belirli işlem süreçleri ve basamakları olan PTÖY literatürde bu öğrenciler için önerilen öğrenme yaklaşımlarından en uygun olanıdır. Öğrenciler bu yöntemle grupla konunun tamamını ya da konun belli bir yönünü derinlemesine araştırma yaparak inceler. Öğrenciler kendi aralarında işbölümü yaparlar. Bu bağlamda gerek normal zihinsel yetilere sahip öğrencilerde gerekse zihinsel yetileri zayıf öğrencilerde PTÖY sosyal becerilerin gelişmesine de katkı sağlayabilir. 
Çevik, M., \& Çevik, Ö. (2016). Proje tabanlı öğrenme yaklaşımının hafif düzeyde zihinsel yetersiz öğrencilerin sosyal becerilerine, akademik başarılarına ve problem davranışlarına olan etkisi. Journal of Human Sciences, 13(3), 48494860. doi: $10.14687 /$ ihs.v13i3.4195

Özellikle engelli çocukların sosyal becerileri engelli olmayan akranlarına göre sınırlıdır ve bu sınırlılık hem akranlar hem de yetişkinlerle etkileşim kurmada çeşitli problemlere yol açmaktadır (Sabornie ve Beard, 1990). Bu çocuklar, akranları ile sosyal etkileşime girmek için daha az girişimde bulunmakta akranlarının etkileşim çabalarına onların anlamadığ1 şekilde tepkiler verebilmektedirler (Beckman ve Kohl, 1987; Guralnick ve Groom, 1987). Ayrıca iletişim becerilerinin sinırlı olması da, sosyal etkileşimlerini azaltmaktadır (Guralnick, 1990). Sosyal statü farklılığı başarıyı etkilediği, sosyal kabulün ise çocuğun grupta akranları ile çalışması ve gerektiği durumlarda akranlarından yardım alabilmesi ile ilişkili görülmektedir. Akademik ortamlarda akranları tarafindan kabul edilmeyen çocuklar genellikle okulu sevmemekte ve kabul gören akranları kadar başarılı deneyimler yaşamamaktadırlar (Snell ve Janney, 2000). Bu nedenlerle engelli öğrencilerin akranlarından gerekli desteği alabilecekleri sosyal çevreyi oluşturabilmeleri için sosyal beceri öğretimi gerekli görülmektedir. Öğrencilerin sergiledikleri problem davranışlar sosyal beceri yetersizlikleri ile ilişkilidir ve çocukluk döneminde sosyal problemler yaşayan hem engelli hem de engelli olmayan bireylerin, yetişkinlik dönemlerinde içselleştirilmiş ve dişsallaştırılmış problemler yaşama riskleri daha fazladır (Clegg ve Standen, 1991). PTÖY temel alınarak planlanmış bir dersin; bu öğrencilerin yaratıcıllğını, öğrenme becerilerini, kendilerine olan güven duygularını ve sosyaltelerini geliştireceği düşünülmektedir. Bu bağlamda fen bilimleri dersinin yapısı düşünüldüğünde PTÖY’nin bu ders kapsamında uygulanması ve zihinsel yetersiz öğrencilerin akademik başarılanını, sosyal becerilerini ve problem davranışlarını ne derece etkilediği bu araştırmanın genel amacını oluşturmuştur.

Araştırmada şu sorulara cevap aranmıştır:

1. Üçüncü sınıf, fen bilimleri dersi, "ben ve çevrem" konusuna yönelik PTÖY baz alınarak gerçekleştirilen öğretim sürecinin hafif düzeyde zihinsel yetersiz öğrencilerin sosyal becerilerine etkisi varmı dir?

2. Üçüncü sınıf, fen bilimleri dersi, "ben ve çevrem” konusuna yönelik PTÖY baz alınarak gerçekleştirilen öğretim sürecinin hafif düzeyde zihinsel yetersiz öğrencilerin poblem davranışlarına etkisi var midir?

3. Üçüncü sınıf, fen bilimleri dersi, "ben ve çevrem" konusuna yönelik PTÖY baz alınarak gerçekleştirilen öğretim sürecinin hafif düzeyde zihinsel yetersiz öğrencilerin sınıf içi akademik yeterliliklerine etkisi var mıdır?

\section{YÖNTEM}

\section{Araştırma Modeli}

$\mathrm{Bu}$ araştırmada, deneme öncesi modellerden tek grup ön test son test deseni kullanılmıştır. $\mathrm{Bu}$ modelde seçkisizlik ve eşleştirme yoktur. Modelin simgesel görünümü aşağıdaki gibidir (Büyüköztürk vd., 2008):

\begin{tabular}{cccc}
\hline Grup & Öntest & İşlem & Sontest \\
G & O1 & $\mathrm{X}$ & O2 \\
\hline
\end{tabular}

$\mathrm{G}$, işlem yapılan grubu; O1, deney grubundan alınan ön ölçümü; $\mathrm{X}$, deneysel işlemi; O2 ise deney grubundan alınan son ölçümü göstermektedir (Büyüköztürk vd., 2008). 
Çevik, M., \& Çevik, Ö. (2016). Proje tabanlı öğrenme yaklaşımının hafif düzeyde zihinsel yetersiz öğrencilerin sosyal becerilerine, akademik başarılarına ve problem davranışlarına olan etkisi. Journal of Human Sciences, 13(3), 48494860. doi: $10.14687 /$ ihs.v13i3.4195

\section{Katılımcilar}

Araştırmanın katılımcılarını Karamanoğlu Mehmetbey Üniversitesi Eğitim Fakültesi Pupa Öğrenci Entegrasyon Birimi projesine gelen 3. sınıf hafif düzeyde zihinsel engele sahip 10 öğrenci oluşturmuştur. Öğrenciler Karaman Rehberlik Araşturma Merkezi (R.A.M.) işbirliği ile öğrenci raporları doğrultusunda seçilmiştir.

\section{Veri Toplama Arac1}

Çalışmada verilerin toplanması için Gresham ve Elliot (1990) tarafından geliştirilen, Özok ve Sucuoğlu (1990) tarafindan Türkçe’ye uyarlanan Sosyal Beceri Derecelendirme Sistemi (SBDS) öntest - sontest olarak uygulanmışır. Ölçme aracı ilkokul 1- 3. sınıf kaynaştırma öğrencileri için uygundur. SBDS ile sosyal beceri yetersizlikleri ve bu yetersizliklere paralel olarak ortaya çıan akademik yetersizlikler de değerlendirilmekte, bunun yanı sıra sosyal beceriler, akademik başarı ve problem davranışlar arasındaki ilişkiye ilişkin de bilgi edinilmektedir (Gresham ve Elliot, 1990). SBDS, okul öncesi ve ilköğretim öğrencilerinin sosyal becerileri ve bu becerilerle ilişkili olduğu kabul edilen davranış problemleri ile akademik yeterliliklerini belirlemek amacıyla geliştirilmiştir. Sosyal beceri dereceleme sisteminde üç ayrı ölçek bulunmaktadır: Sosyal beceri ölçeği, problem davranış ölçeği ve akademik yeterlilik ölçeği.

\section{Sosyal Beceri Derecelendirme Sistemi (SBDS) Geçerlik Analizleri}

\section{Sosyal Beceri Alt Ölçeği:}

Faktör analizleri: Ölçek 3 alt faktörden oluşmakta ve bu faktörler toplam varyansın \%59. 75 ini açıkladığı görülmüştür.

\section{Problem Davranış Alt Ölçeği}

Faktör analizleri: Ölçek 3 alt faktörden oluşmakta ve bu faktörler toplam varyansin \% \%61. 79 unu açıkladığı görülmüştür.

\section{Akademik Yeterlik Alt Ölçeği}

Faktör analizleri: Ölçek tek alt faktörden oluşmakta ve bu faktörün toplam varyansın \% $\%$. 06 unu açıkladığı görülmüştür

Ayrıca tüm ölçekte yer alan maddelerin, madde toplam korelasyon katsayılarının da .40 ile .77 arasında değiştiği görülmüştür. Analiz sonuçlarına göre, sosyal beceri ölçeği toplam puanları ile problem davranışlar ölçeği toplam puanları arasında yüksek ve ters bir ilişki $(\mathrm{r}=-.713, \mathrm{p}=.000)$; akademik yeterlilik puanlan ile de yüksek ve doğru bir ilişki vardır $(\mathrm{r}=.712, \mathrm{r}=.000)$. Benzer şekilde problem davranıs puanları ile akademik yeterlilik puanları arasında da anlamlı ve ters bir ilişki olduğu görülmüştür $(\mathrm{r}=-.485, \mathrm{p}=.000)$ Özok ve Sucuoğlu (1990).

\section{Sosyal Beceri Derecelendirme Sistemi (SBDS) Güvenirlik Analizleri}

\section{Sosyal Beceri Alt Ölçeği:}

Sosyal Beceriler Ölçeğinin toplam puan için Cronbach Alfa katsayısı .96, birinci faktör için .91 , ikinci faktör için .93 ve üçüncü faktör için .84 olarak bulunmuştur.

\section{Problem Davranış Alt Ölçeği}

Problem davranışlar ölçeğinin toplam puan için Cronbach Alfa katsayısı .90, birinci faktör için .93, ikinci faktör için .86 olarak bulunmuştur.

\section{Akademik Yeterlik Alt Ölçeği}

Akademik Yeterlilik Ölçeğinin toplam puan için Cronbach Alfa katsayısı ise .97 olarak bulunmuştur. Tüm analizlerin sonuçları, SBDS'nin ilkokul öğrencilerinin sosyal becerilerini değerlendirmede geçerli ve güvenilir bir ölçek olarak kullanılabileceğini göstermektedir (Özok ve Sucuoğlu, 1990).

\section{Proje Tabanlı Öğrenme Yaklaşımı İşlem Basamakları}

Çalışma kapsamında PTÖY'nin fen bilimleri dersinde hangi konuda verilmesine fen bilimleri dersi uzman öğretmeni, rehberlik servisi ve özel eğitim öğretmeni birlikte kararlaştırmıştır. Karar verilen konu ile ilgili bir takvim oluşturulmuştur. Oluşturulan takvim 1şı̆̆ında gerçekleştirilecek faaliyetler ve iş bölümleri netleştirilerek adım adım projeye geçilmiştir. Çalışmada öğrencilere 3. sınıf fen bilimleri dersinin "Ben ve Çevrem" konusu proje tabanlı öğrenme yaklaşımı 
Çevik, M., \& Çevik, Ö. (2016). Proje tabanlı öğrenme yaklaşımının hafif düzeyde zihinsel yetersiz öğrencilerin sosyal becerilerine, akademik başarılarına ve problem davranışlarına olan etkisi. Journal of Human Sciences, 13(3), 48494860. doi: $10.14687 /$ ihs.v13i3.4195

ile 3 hafta boyunca işlenmiş ders öncesinde ve sonrasında ölçek uygulanarak elde edilen puanlar arasındaki anlamlılı̆ga bakılmıştır.

PTÖY nin uygulama basamakları aşağıdaki şekilde gerçekleştirilmiştir:

1. Öğrenciler fen bilimleri öğretmeninden konu ile ilgili ön bilgi almıslar ve beyin firtınası yapmışlardır.

2. Öğrenciler proje konusu tespitinden sonra internette tarama yapmışlardır.

3. Proje için malzemeler belirlenerek iş takvimi oluşturulup kaç haftalık bir süreçte tasarımın tamamlanabileceği öngörülmüştür.

4. Çalışmalara fen bilimleri dersliğinde başlanmış, el sanatları veya görsel sanatlar atölyesinde çalışmalara devam edilmiştir.

5. Konu kapsamında geri dönüşüm kutu tasarımları tamamlandıktan sonra öğrencilerden projelerini sunulması istenmiştir.

\section{Verilerin Analizi}

Verilerin çözümlenmesinde SPSS 16.0 paket programından yararlanılmıştır. Bu bağlamda ilişkili ölçümler için non parametrik analiz yöntemlerinden Wilcoxon Issaretli Sıralar Testiyle anlamlılık düzeyine, standart sapma ve ortalamalarına bakılmıştır.

\section{BULGULAR VE YORUMLAR}

PTÖY ile işlenen ders neticesinde hafif düzeyde zihinsel engele sahip öğrencilerin sosyal beceri ölçeği puan ortalamaları Tablo 1'de verilmiştir.

Tablo 1. Sosyal Beceri Ölçeği Ön Test Son Test Puanlarına İlişkin Ortalama ve Standart Sapmaları

\begin{tabular}{cccc}
\hline & $\mathbf{N}$ & Ortalama & Standart Sapma \\
\hline Ön Test & 10 & 25.5 & 9.65 \\
Son Test & 10 & 37.5 & 9.75 \\
\hline
\end{tabular}

Tablo 1 de görüldüğü üzere PTÖY ile işlenen ders neticesinde hafif düzeyde zihinsel engele sahip öğrencilerin sosyal beceri ölçeği puan ortalamalarında artış olmuştur. Ortalama puanlar ön testte 25.5 iken son testte 37.5 e yükselmiştir. PTÖY uygulanan katılımcıların ön test son test puanlarına ilişkin wilcoxon işaretli sıralar testi sonuçları Tablo 2' de verilmiştir.

Tablo 2. Sosyal Beceri Ölçeği Öntest ve Sontest Puanlarına İlişkin Wilcoxon İşaretli Sıralar Testi Sonuçları

\begin{tabular}{cccccc}
\hline Ön test Son test & $\mathbf{N}$ & $\begin{array}{c}\text { Sira } \\
\text { Ortalaması }\end{array}$ & $\begin{array}{c}\text { Sira } \\
\text { Toplami }\end{array}$ & $\mathbf{z}$ & $\mathbf{p}$ \\
\hline Negatif Sıra & 1 & .00 & .00 & & \\
Pozitif Sıra & 9 & 6 & 54 & -2.71 & .00 \\
Eşit & 0 & & & & \\
\hline
\end{tabular}

Katılımcıların PTÖY sonrasında öntest ve sontest puanları arasındaki farkın son test lehine anlamlı olduğu görülmektedir [ $\mathrm{z}=2.71, \mathrm{p}<.05]$. Elde edilen bu bulgudan, öğrencilerinin PTÖY uygulama süreci sonunda sosyal becerilerinin anlamlı bir şekilde arttığı sonucuna ulaşılabilir. 
Çevik, M., \& Çevik, Ö. (2016). Proje tabanlı öğrenme yaklaşımının hafif düzeyde zihinsel yetersiz öğrencilerin sosyal becerilerine, akademik başarılarına ve problem davranışlarına olan etkisi. Journal of Human Sciences, 13(3), 48494860. doi:10.14687/ihs.v13i3.4195

PTÖY ile işlenen ders neticesinde hafif düzeyde zihinsel engele sahip öğrencilerin problem davranış ölçeği puan ortalamaları Tablo 3’te verilmiştir.

Tablo 3. Problem Davranış Ölçeği Ön Test Son Test Puanlanına İlişkin Ortalama ve Standart Sapmalar1

\begin{tabular}{cccc}
\hline & $\mathbf{N}$ & Ortalama & Standart Sapma \\
\hline Ön Test & 10 & 15.2 & 4.66 \\
Son Test & 10 & 12.1 & 6.75 \\
\hline
\end{tabular}

PTÖY ile işlenen ders neticesinde hafif düzeyde zihinsel engele sahip öğrencilerin problem davranış ölçeği puan ortalamalanında düşüş olmuştur. Ortalama puanlar ön testte 15.2 iken son testte 12.1 e düşmüştür.

PTÖY uygulanan katılımcıların ön test son test puanlarına ilişkin wilcoxon işaretli sıralar testi sonuçları Tablo 4' te verilmiştir.

Tablo 4. Problem Davranış Ölçeği Öntest ve Sontest Puanlarına İlişkin Wilcoxon İşaretli Sıralar Testi Sonuçlar1

\begin{tabular}{cccccc}
\hline Ön test Son test & $\mathbf{N}$ & $\begin{array}{c}\text { Sıra } \\
\text { Ortalaması }\end{array}$ & $\begin{array}{c}\text { Sıra } \\
\text { Toplamı }\end{array}$ & $\mathbf{z}$ & $\mathbf{p}$ \\
\hline Negatif Sıra & 7 & 5.71 & 40 & & \\
Pozitif Sıra & 3 & 5 & 15 & -1.27 & .20 \\
Eşit & 0 & & & & \\
\hline
\end{tabular}

Katılımcıların PTÖY sonrasında öntest ve sontest puanları arasındaki farkın anlaml olmadiğı görülmektedir [ $\mathrm{z}=1.27, \mathrm{p}>.05]$. Elde edilen bu bulgudan, öğrencilerinin PTÖY uygulama süreci sonunda problem davranış ölçeği puandaki azalmanın anlamlı ölçüde olmadığı sonucuna ulaşılabilir.

PTÖY ile işlenen ders neticesinde hafif düzeyde zihinsel engele sahip öğrencilerin akademik yeterlilik ölçeği puan ortalamaları Tablo 5’te verilmiştir

Tablo 5. Akademik Yeterlilik Ölçeğinin Ön Test Son Test Puanlarına İlişkin Ortalama ve Standart Sapmalar1

\begin{tabular}{cccc}
\hline & $\mathbf{N}$ & Ortalama & Standart Sapma \\
\hline Ön Test & 10 & 20.5 & 10.2 \\
Son Test & 10 & 32.3 & 13.1 \\
\hline
\end{tabular}

PTÖY ile işlenen ders neticesinde hafif düzeyde zihinsel engele sahip öğrencilerin akademik yeterlilik ölçeğinin puan ortalamalarında artış olmuştur. Ortalama puanlar ön testte 20.5 iken son testte 32.3 e yükselmiştir.

PTÖY uygulanan katılımcıların ön test son test puanlarına ilişkin wilcoxon işaretli sıralar testi sonuçları Tablo 6' da verilmiştir. 
Çevik, M., \& Çevik, Ö. (2016). Proje tabanlı öğrenme yaklaşımının hafif düzeyde zihinsel yetersiz öğrencilerin sosyal becerilerine, akademik başarılarına ve problem davranışlarına olan etkisi. Journal of Human Sciences, 13(3), 48494860. doi: $10.14687 /$ ihs.v13i3.4195

Tablo 6. Akademik Yeterlilik Ölçeğinin Öntest ve Sontest Puanlarına İlişkin Wilcoxon İşaretli Sıralar Testi Sonuçları

\begin{tabular}{cccccc}
\hline Ön test Son test & $\mathbf{N}$ & $\begin{array}{c}\text { Sıra } \\
\text { Ortalaması }\end{array}$ & $\begin{array}{c}\text { Sıra } \\
\text { Toplamı }\end{array}$ & $\mathbf{z}$ & $\mathbf{p}$ \\
\hline Negatif Sıra & 1 & 1 & 1 & & \\
Pozitif Sıra & 9 & 6 & 54 & -2.70 & .00 \\
Eşit & 0 & & & & \\
\hline
\end{tabular}

Katılımcıların PTÖY sonrasında öntest ve sontest puanları arasındaki farkın son test lehine anlamlı olduğu görülmektedir $[\mathrm{z}=2.70, \mathrm{p}<.05]$. Elde edilen bu bulgudan, öğrencilerinin PTÖY uygulama süreci sonunda akademik yeterliklerinin anlamlı bir şekilde arttığ1 sonucu yorumu yapilabilir.

\section{TARTIŞMA, SONUÇ VE ÖNERİLER}

Çalışmada hafif düzeyde zihinsel engele sahip öğrencilerle fen bilimleri dersinde gerçekleştirilen PTÖY, merkezinde uygulamaları, etkinlikleri ve sosyal çalışmaları içermesinden dolayı çıtıları pozitif yönde olmuştur. Sosyal beceri ve akademik yeterlik alt ölçeklerinin puan ortalamaları arasında anlamlı düzeyde artsş görülmüştür. Bunun tersine problem davranış alt ölçeğinin puan ortalamalarında düşüş olmuştur. Alanyazında uygulamalı fen eğitiminin hafif düzeyde zihinsel engele sahip öğrencilere birçok açıdan pozitif etkisinin olduğunu açıklayan çalışmalar yer almaktadır (Bay, Staver, Bryan, \& Hale, 1992; Çevik, 2016; Çevik ve Düzgün, 2015; Dalton, Morocco, \&Tivnan, 1997; McCarthy, 2005). Yine Amerika'da önde gelen bilim kuruluşları uygulamalı fen öğreniminin öğrencilerde kalıcı öğrenmelere neden olduğunu onaylamakta olup öğrenme çıttılarının seviyelerinin üzerine ulaşabildiğini söylemektedir (Rutherford \& Ahlgren,1990). Tezcan (2012) de yaptığı tez çalışmasında bilişim teknolojileri kullanılarak hafif düzeyde zihinsel engeli olan öğrencilere, günlük hayatlarını kolaylaştırabilecek ve sorunları daha rahat çözmelerine yardımcı olabilecek fen ve matematik bilgilerinin, etkili ve kalıcı bir biçimde öğrenmelerini sağlamak istemiştir. Çalışma sonunda öğrencilerin akademik başarısını ve öğrenmelerindeki kalıcıllı̆ını arttırdığ1 sonucuna ulaşılmıştır. Temelinde uygulama olan farklı öğretim yöntemleri hafif düzeyde zihinsel engelli öğrencilerin akademik başarılarını artırdığı çalısmamızın sonuçlarını da destekler niteliktedir.

Melber, (2004) özel gereksinimli öğrencilerin bilimsel okuryazarlıkta kapasitelerini artırmada, günlük hayatlarında onların çevrelerinde gerçekleşen olayların, öğrenme ortamlarına dahil edilmesinin gerekli olduğunu rapor etmiştir. Temelinde uygulama olan farklı öğretim yöntemleri hafif düzeyde zihinsel engelli öğrencilerin, sosyal becerilerini artırdığı çalışmamızın sonuçlarını da destekler niteliktedir.

Gürgür (2005) yaptığ1 çalışmada kaynaştırma uygulamasının yapıldığ1 sınıfta işbirliği ile öğretim yaklaşımını incelemiş çalışma sonucunda özel gereksinimli öğrencilerin başarılarının arttı̆̆ını ayrıca bu öğrencilerin dersleri dinlemeleri, etkinliklere katılmaları, arkadaşlarıyla ve öğretmenlerle etkili iletişim kurmalarında da gelişmeler gösterdikleri sonucunu elde etmiştir. İşbirlikli öğrenmeyi de içine alan PTÖY, bu öğrenciler için eğitim ve öğretimde kullanılabilecek bir yöntem olabileceğini göstermektedir. PTÖY ile elde ettiğimiz sosyal beceri ve akademik başarılarındaki pozitif ilerleme ve problem davranış puanlarındaki düşüş çalısmamızı destekler niteliktedir. Baki (2014) ve Morin ve Miller (1998), yaptıkları çalışmalarda, şemaya dayalı öğretim stratejisinin zihinsel yetersizliği olan öğrencilerin matematikte sözel problemi çözme performanslarını artırdığını tespit etmişlerdir. İlik (2009) de hafif düzeyde zihinsel engele sahip öğrencilere yönelik fen bilimleri dersinde kavramların kazandırılmasında doğrudan öğretim yöntemini kullanmıştır. Çalışmasında güneş sistemi konusunu 
Çevik, M., \& Çevik, Ö. (2016). Proje tabanlı öğrenme yaklaşımının hafif düzeyde zihinsel yetersiz öğrencilerin sosyal becerilerine, akademik başarılarına ve problem davranışlarına olan etkisi. Journal of Human Sciences, 13(3), 48494860. doi: $10.14687 /$ ihs.v13i3.4195

tercih etmiş ve tüm denekler için doğrudan öğretimin etkili olduğu ortaya çıkmıştır. Bu bulgu çalışmada ulaşılan sonuçlar ile benzerlik göstermektedir.

$\mathrm{Bu}$ çalışmada; PTÖY öncesi ve sonrasında SBDS ölçeği kullanılarak öğrencilerin sosyal beceri, akademik yeterlik ve problem davranış gibi alanlardaki puanların ortalamalarının karşılaştırılarak nicel olarak yorumlamasına gidilmiştir. Çalışmada öğrencilerin PTÖY sürecinde araşturmacılar tarafindan gözlem yaparak ta sosyal becerilerindeki değişiklikler hakkında veri toplanması, çalışmanın bilimsel zeminini güçlendirebilirdi. Çalışmada fen bilimleri dersinde bir öğretim yöntemi olarak uygulanan proje tabanlı öğrenme yaklaşımının yerine farklı yöntemler de kullanılabilir. İçerisinde etkinliklerin, uygulamaların, sosyal çalışmaların yer aldığı farklı öğrenme yaklaşımları kullanılarak derslerin işlenmesi bu öğrencilerin sosyal becerilerinin güçlenmesine dolayısıyla akademik başarılarında artmaya, problem davranışlarında azalmaya neden olması mümkündür.

Yine PTÖY'nin fen bilimleri yerine farklı derslerde de uygulanıp bu öğrencilerin akademik başarılarını, sosyal becerilerini ve problem davranışlarını ne derecede etkilediği araştırma konusu olabilir. Çalışmada kullanılan PTÖY yerine fen bilimleri dersine uygun farklı öğretim yöntemleri kullanılabilir.

\section{KAYNAKÇA}

Akınoğlu, O. (2001). Eleştirel düşünme becerilerini temel alan fen bilgisi öğretiminin öğrenme ürünlerine etkisi. (Yayımlanmamış Doktora Tezi). Hacettepe Üniversitesi, Eğitim Bilimleri Enstitüsü, Ankara.

Altun, S. (2008). Proje tabanlı öğretim yönteminin öğrencilerin elektrik konusu akademik başarılarına, fiziğe karşı tutumlarına ve bilimsel işlem becerilerine etkisinin incelenmesi. Doktora Tezi. Atatürk Üniversitesi Fen Bilimleri Enstitüsü, Erzurum.

Baki, K. (2014). Şemaya dayalı öğretim stratejisinin zihinsel yetersizliği olan öğrencilerin matematikte sözel problem çözme becerilerine etkililiği. Yayınlanmamış Yüksek Lisans Tezi, Anadolu Üniversitesi Eğitim Bilimleri Enstitüsü, Eskişehir.

Baran, M. (2007). Proje tabanlı öğrenme modelinin fizik öğretmenliği ikinci sınıf öğrencilerinin elektrostatik konusu başarısına ve fiziğe yönelik tutumlarına etkisi üzerine bir araştırma. Yüksek Lisans Tezi, Dicle Üniversitesi Fen Bilimleri Enstitüsü, Diyarbakır.

Batu, S., Kırcalı-İftar, G. ve Uzuner, Y. (2004). Özel Gereksinimli Öğrencilerin Kaynaşturıldığı Bir Kız Meslek Lisesindeki Öğretmenlerin Kaynaştırmaya İlişkin Görüş ve Önerileri, Ankara Üniversitesi Ë̆itim Bilimleri Fakültesi Özel Eğitim Dergisi, 5(2), 33-50.

Bay, M., Staver, J., Bryan, T. and Hale, J. (1992). Science in struction for the mildly handicapped: Direct instruction versus discovery teaching. Journal of Research in Science Teaching, 29, 555570.

Beckman, P. J., \& Kohl, F. L. (1987). Interaction of preschoolers with and without handicaps in integrated and segragated settings: A longitudinal study. Mental Retardation, 25, 5-11.

Benzer, E. (2010). proje tabanl ögrenme yaklaşımylla baz̧rlanan çevre eğitimi dersinin fen bilgisi ögretmen adaylarmm cevre okuryazarlğgna etkisi. Doktora Tez̨, Marmara Üniversitesi Eğitim Bilimleri Enstitüsü, İstanbul.

Bigge, J. L., Best, S. J. and Heller, K. W. (2001). Teaching individuals with physical, health, or multiple disabilities. 4th ed. Upper Saddle River, NJ: Merrill PrenticeHall.

Bilen, M. (2002). Plandan uygulamaya ögretim. Ankara: Anı yayınc1lı.

Büyüköztürk, Ş., Çakmak, E. K., Akgün, Ö. E., Karadeniz, Ş. ve Demirel, F. (2008). Bilimsel Araştırma Yöntemleri. Ankara: Pegem A Yayincilik.

Cawley, J. F. (1994). Science for students with disabilities. Remedial and Special Education, 15, 67-71

Clegg, J. A., \& Standen, P. J. (1991). Friendship among adults who have developmental disabilities. American Journal on Mental Retardation, 95, 663- 667. 
Çevik, M., \& Çevik, Ö. (2016). Proje tabanlı öğrenme yaklaşımının hafif düzeyde zihinsel yetersiz öğrencilerin sosyal becerilerine, akademik başarılarına ve problem davranışlarına olan etkisi. Journal of Human Sciences, 13(3), 48494860. doi:10.14687/ihs.v13i3.4195

Çakallıŏ̆lu, S. (2008). Proje tabanlı öğrenme yaklaşımına dayalı fen bilgisi öğretiminin akademik başarı ve tutuma etkisi. Yayınlanmamış Yüksek Lisans Tezi. Çukurova Üniversitesi Sosyal Bilimler Enstitüsü, Adana.

Çevik, M. (2016). Fen bilimleri dersinde proje tabanlı öğrenme yaklaşımının ilkokulda öğrenim görmekte olan hafif düzeyde zihinsel engele sahip öğrencilerin akademik başarılarına ve tutumlanna etkisi. NWSA Education Sciences 11 (1), 36-48.

Çevik, M. and Düzgün, M. (2015 Ekim) Effects of the project-based learning approaches on academic achievement and attitude of students studying at first stage of primary school with light mental barriers in mathematics lesson. International Conference on Primary Education. Nevşehir, Turkey.

Dalton, B., Morocco, C. C., Tivnan, T. and Mead, P. L. R. (1997). Supported inquiry science: Teaching for conceptual change in urban and suburban classrooms. Journal of Learning Disabilities, 30, 670-684.

Demir, K. (2008). Bütünleştirilmiş öğretim programının işbirliğine dayalı ve proje tabanlı öğrenme yaklaşımıyla uygulanmasının etkililiği. Doktora Tezi. Hacettepe Üniversitesi Sosyal Bilimler Enstitüsü, Ankara.

Field, A. (2005). Discovering statistics using SPSS (Second Edition). Thousands Oak, CA: SAGE Publications Inc.

Girgin, D. (2009). Canlılar ve hayat ünitesinde proje tabanlı öğrenme yaklaşımının ilköğretim 5. sınıf öğrencilerinin akademik başarı ve tutumlanı üzerine etkisi. Yüksek Lisans Tezi, Dokuz Eylül Üniversitesi Ĕ̆itim Bilimleri Enstitüsü, İzmir.

Gresham, F. M., \& Elliot, S. N. (1990). Social Skills Rating System. Circle Pines: American Guidance Services.

Guralnick, M. (1990). Social competence and early intervention. Journal of Early Intervention, 14, 3-14.

Guralnick, M., \& Groom, J. M. (1987). The peer relations of mildly delayed and nonhandicapped preschool children in mainstreamed play groups. Child Development, 58, 1558-1572.

Gürgür, H. (2005). Kaynaştırma uygulamasının yapıldığı ilköğretim sınıfinda işbirliği ile öğretim yaklaşımının incelenmesi. Yayınlanmamış Doktora Tezi. Ankara Üniversitesi, Eğitim Bilimleri Enstitüsü. Ankara.

İlik, Ş. Ş. (2009). Hafif düzeyde öğrenme güçlüğüne sahip öğrencilerde doğrudan öğretim yönteminin fen ve teknoloji dersine ilişkin kavramların öğretiminde etkililiğinin değerlendirilmesi. Yayınlanmamış Yüksek Lisans Tezi, Selçuk Üniversitesi, Sosyal Bilimler Enstitüsü. Konya.

Korkmaz, H. (2002). Fen eğitiminde proje tabanlı öğrenmenin yaratıcı düşünme, problem çözme ve akademik risk alma düzeylerine etkisi. Doktora Tezi, Hacettepe Üniversitesi Sosyal Bilimler Enstitüsü, Ankara.

Korkmaz, H. ve Kaptan, F. (2002). Fen eğitiminde proje tabanlı öğrenme yaklaşımının ilköğretim öğrencilerinin akademik başarı, akademik benlik kavramı ve çalışma sürelerine etkisi. Hacettepe Üniversitesi Ë̈itim Fakültesi Dergisi (22), 91-97.

Mastropier1, M. A. and Scruggs, T. E. (1994). Text-based vs. activities-oriented science curriculum: Implications for students with disabilities. Remedial and Special Education, 15, 72-85.

McCarthy, C. B. (2005). Effects of thematic-based, hands-on science teaching versus a textbook approach for students with disabilities. Journal of Research in Science Teaching, 42, 245-263.

MEB. (2013). İlkögrretim Kurumlar (Illkokullar ve Ortaokullar) Fen Bilimleri Dersi (3, 4, 5, 6, 7 ve 8. Sinflar) Ögretim Programı, Ankara: MEB Yayınevi.

Melber, L. M. 2004. Inquiry for everyone: Authentic science experiences for students with special needs. Teaching Exceptional Children Plus,1 (2).

Morin, V. A. and Miller, S. P. (1998). Teaching multiplication to middle school students with mental retardation. Education and Treatment of Children, 21, 22-36. 
Çevik, M., \& Çevik, Ö. (2016). Proje tabanlı öğrenme yaklaşımının hafif düzeyde zihinsel yetersiz öğrencilerin sosyal becerilerine, akademik başarılarına ve problem davranışlarına olan etkisi. Journal of Human Sciences, 13(3), 48494860. doi:10.14687/ihs.v13i3.4195

Özdener, N. ve Özçoban, T. (2004). Bilgisayar eğitiminde çoklu zeka kuramına göre proje tabanlı öğrenme modelinin öğrenci başarısı üzerine etkisi. Kuram ve Uygulamada Ë̆̈tim Bilimleri, 4(1), $147-170$.

Özsoy, Y., Özyürek, M. ve Eripek, S. (1997). Özel eğitime mubtac çocuklar. Ankara: Karatepe Yayınları.

Patton, J. R. 1995. Teaching science to students with special needs. Teaching Exceptional Children,27 (4): 4-6.

Rutherford, F. J. and Ahlgren, A. (1990). Science for all americans. New York: Oxford University Press. Saban, A. (2000). Yaratıcliğ gelistirme teknikleri. İzmir: Kanyllmaz Matbaası.

Sabornie, E. J., \& Beard, G. H. (1990). Teaching social skills to students with mild handicaps. Teaching Exceptional Children, 23(1), 35-38.

Scruggs, T. E., Mastropieri, M. A. And Bonn, R. (2008). Science education for students with disabilities: a review of recent research. Studies in Science Education, 32:1, 21-44.

Snell, M. E., \& Janney, R. (2000). Teachers' guides to inclusive practices: Social relationships and peer support. Baltimore: Paul H. Brookes Publishing Co.

Sucuoğlu, B. ve Özokuçu, O. (2005). Kaynaştırma öğrencilerinin sosyal becerilerinin değerlendirilmesi. Ankara Üniversitesi Ë̆itim Bilimleri Fakültesi Özel Eğitim Dergisi 2005, 6 (1) 41-57

Tezcan, C. (2012) Zihinsel engelli çocuklara web destekli uzaktan eğitim sistemi kurulması: matematik ve fen bilgisi dersleri uygulaması. Yayınlanmamıs Yüksek Lisans Tezi. Trakya Üniversitesi, Fen Bilimleri Enstitüsü. Edirne.

Woodward, J. (1994). The role of models in secondary science instruction. Remedialand Special Education, 15, 94-104.

\section{Extended English Abstract}

Individuals with mental disabilities are classified in three groups that are trainable-teachable, advanced and very severely mentally disabled individuals in itself depending on the degree of the disorder (Özsoy, Özyürek ve Eripek, 1997). The mainstreaming approach, that is considered as individuals with mild mental disabilities to continue in general education schools with their peers provided that they receive special education services, is being widely adopted last thirty years and as a result of this, students with disabilities in many countries are trained in general education schools with their peers without disabilities (Sucuoğlu ve Özokçu, 2005). However, this is not only a process that involves placing individuals into the regular classrooms. It also includes organizing educational environment and program of these students and providing individuals who need in support and regulation services in this process in order to maximize their level of development. In recent years, it is considered that science education holds an important place in educating students with mild mental disabilities and intensive work is done in this context (Cawley, 1994; Mastropieri \& Scruggs, 1994; Patton, 1993; 1995). However, which method, approach or curriculum is the most appropriate to implement in this course for students with mild mental disabilities is crucial to answer (Scruggs, Mastropieri, and Bonn, 2008). In this regard, project-based learning approach (PBLA) that contains practices and interrogative features as well as certain process procedures and steps is the most appropriate proposed learning approach. In this context, the aim of this study is to determine the impact of science education planned with PBLA on social skills of students, their academic qualifications and problematic behaviors. 
Çevik, M., \& Çevik, Ö. (2016). Proje tabanlı öğrenme yaklaşımının hafif düzeyde zihinsel yetersiz öğrencilerin sosyal becerilerine, akademik başarılarına ve problem davranışlarına olan etkisi. Journal of Human Sciences, 13(3), 48494860. doi: $10.14687 /$ ihs.v13i3.4195

\section{Method}

In this study, the one group pretest-posttest design, which is a pre-experimental model, was used. The participants of the research consisted of $3^{\text {rd }}$ grade10 students with mild mental disabilities from Pupa Student Integration Unit, Karamanoğlu Mehmetbey University, Education Faculty. In the study, Social Skills Rating System (SSRS) developed by Gresham and Elliot (1990) and adapted to Turkish by Özokçu and Sucuoğlu (2005), was used as pretest and posttest. The scale is proper for $1^{\text {st }}-3^{\text {rd }}$ grade mainstreaming students in primary schools. Social skill incompetence and academic incompetence emerging in parallel to this incompetence are assessed as well as information is obtained by SSRS regarding the relation between academic achievement, social skills and problematic behaviors (Gresham ve Elliot, 1990). SPSS 16.0 software package was used for the data analysis. In this context, significance levels, standard deviation, and mean scores were examined by the Wilcoxon Signed Rank Test for non-parametric analysis methods.

\section{Results}

An increase has been observed in social skills mean scores of students with mild mental disabilities in the course with PBLA. The difference between pretest and posttest scores of participants was found to be statistically significant in favor of the posttest after PBLA [ $z=2.71$, $\mathrm{p}<.05]$. It can be reached from this finding that social skills of students have significantly increased at the end of implementation of PBLA. The decline in problematic behavior scale mean scores of students was observed in the course with PBLA. It was seen that the difference between pretest and posttest scores of participants seems to be insignificant $[\mathrm{z}=1.27, \mathrm{p}>.05]$. It can be reached from this finding that the decrease in problematic behavior scale mean scores of students was insignificant after the implementation of PBLA. There was an increase in students' mean scores of the academic proficiency scale at the end of the course with PBLA. The difference between pretest and posttest scores of participants is significant in favor of the posttest after PBLA [ $\mathrm{z}=2.70, \mathrm{p}<.05]$. It can be reached from this finding that academic proficiencies of students have significantly increased after the implementation of PBLA.

\section{Discussion and Conclusion}

In the study, outcomes of PBLA that was conducted with students with mild mental disabilities in the science class have been positive since it includes activities and social studies at its center. A significant increase was observed between mean scores of social skills and academic proficiency subscales. Conversely, there was a decrease in mean scores of the subscale of problematic behavior. In the literature, there are studies explaining the positive effect of applied science education to students with mild mental disabilities in many ways (Çevik, 2016; Çevik ve Düzgün, 2015; Bay, Staver, Bryan, \& Hale, 1992; Dalton, Morocco, \&Tivnan, 1997; McCarthy, 2005). Güngür (2005) investigated the cooperative learning in the class where the mainstreaming is applied and indicated that the successes of students with special needs increased and these students demonstrated improvements in listening to lectures, participating activities, communicating effectively with peers and teachers. PBLA that also includes cooperative learning indicates that it can be a method to be used in training these students. Positive progress in social skills and academic achievement and a decrease in problematic problems scores that we obtained with PBLA support our study. Collecting data by observations in PBLA process regarding changes in social skills of students could strengthen the scientific basis of the study. Different methods can also be used instead of PBLA as a teaching method in science courses. It is possible that teaching the course using different approaches involving activities, practices, social work can strengthen social skills of these students, thus increase their academic achievements and cause a decrease in problematic behaviors. 